\title{
A Survey on Wireless Network Simulators
}

\author{
Amanjot Singh Toor ${ }^{* 1}$, A. K. Jain ${ }^{2}$ \\ Department of Instrumentation \& Control \\ Dr. B.R Ambedkar National Institute of Technology \\ Jalandhar, Punjab, India \\ *Corresponding author, e-mail: er.amanjot87@gmail.com ${ }^{1}$, jainak@nitj.ac.in ${ }^{2}$
}

\begin{abstract}
The Network simulator helps the developer to create and simulate new models on an arbitrary network by specifying both the behavior of the network nodes and the communication channels. It provides a virtual environment for an assortment of desirable features such as modeling a network based on a specific criteria and analyzing its performance under different scenarios. This saves cost and time required for testing the functionality and the execution of network. This paper has surveyed various Wireless Network Simulators and compared them.
\end{abstract}

Keywords: Open-Source Technology, Network Simulation, Open Source Network simulators, NS2, NS3, J-Sim, OMNeT++, OPNET, QUALNET and MATLAB

\section{Introduction}

Simulation is a technique used for executing the network on to the computer and with this, the behavior of the network is calculated with the help of some mathematical calculations that are used by network organizations [1]. They are used to allow the researchers to develop, test and diagnose network scenarios that are difficult to simulate in the real world. It is basically used to test the new networking protocols or to change the existing protocols under controlled and reproductive environment. Different types of topologies can be designed by using various types of nodes (host, bridges, routers, hubs and mobile units etc) [2].

In the rest of the paper, section 2 describes the taxonomy on simulation, section III includes open source software and network simulator along with features and limitations. Section IV gives the Comparative study of different open source simulators. Finally the last section provides the conclusion.

\section{Taxonomy on Simulation}

Now a day's information society is continuing to emerge and demands for the growth of wireless communication. So for that purpose, future generation wireless networks are necessary to considered with their increasing necessities. The Future generation wireless networks are characterized by a distributed, dynamic, self-organizing architecture. These networks are mainly classified into different types based upon some specific characteristics viz Cognitive Radio Networks, Ad-Hoc/Mesh Networks, Sensor Networks, etc are shown in Figure 1 [3].

These wireless networks are used in various applications viz business, healthcare, military, gaming etc. The exposure of wireless networking has created many open research issues in network design too and many researchers are trying their best in designing the future generation wireless network. 


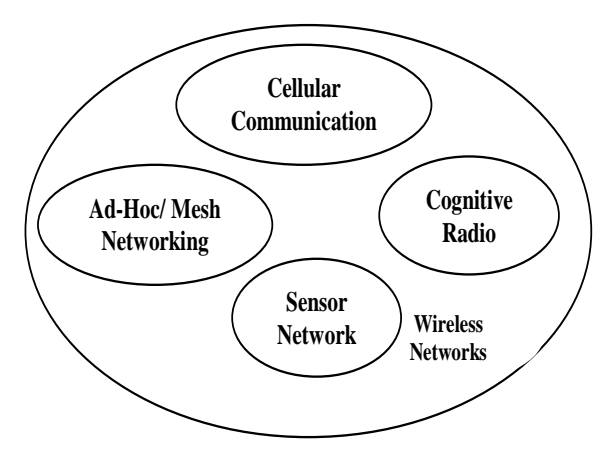

Figure 1. Different kinds of wireless networks

For analyzing the performance of wireless networks as well as wired network, three techniques are used; analytical methods, simulation by computer and test bed measurement or physical measurement [3].

In analytical method, attempts have been made to find the analytical solution to problems with the help of some initial conditions and set of parameters. However, it is a very complex method because lots of mathematical analysis has been done at each layers. Therefore, it is also known as comprehensive model for wireless ad-hoc networks. Also, the construction of test bed for any pre-set network is very costly, un-bearable task and requires a lot of efforts [3].

However, Simulation by computers is the most common method and has proven to be a valuable tool for developing and testing new protocols for wireless network where analytical method is neither applicable nor feasible. Researchers commonly use simulation method for analysis the performance of a system. Simulators are used for the many reasons like lower in cost, ease of implementation and practicality of testing large-scale networks.

The main aim of simulators is to attain "as real as possible" situation in order to make the obtainable result realistic as well as adaptable. In wireless network simulation, three important points have to be considered; firstly, the protocols and algorithms should be free from errors and have been implemented in details, secondly the simulation environment should be realistic and in addition to that a genuine method is used to analyze the collected data. However, it still has some potential pitfalls. So to overcome these, it is necessary to know about different tools that are available and came to know about their benefits and drawbacks [4].

The basic steps to run a simulation are as shown in Figure 2 [3].

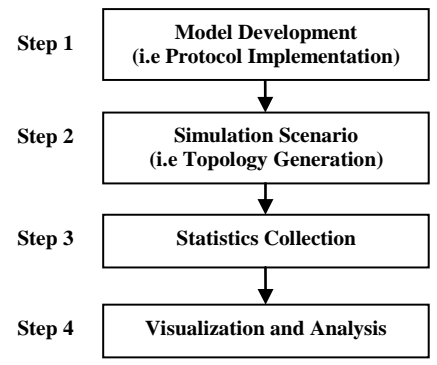

Figure 2. Simulation steps

The first step is to implement a protocol (that is model development); second step is to create a simulation scenario (that is designing a network topology and traffic scenario); third step is the collection of statistics and finally the fourth step is to visualize and analyze the simulation results which is carried out during or after the execution of simulation. The main problem with this method is that no one can make a guess in advance that how many times this 
process should be repeated to have a minimal error. And if the error is found out to be large then this process need to be repeated.

Simulation tools are classified into several norms which are as shown in Figure 3 [5]:

a. Stochastic simulation

Stochastic simulation tool is one of the most realistic simulation tools that will include some randomness along with some time elapsing elements. The main applications of such simulations are to propose a model to observe the traffic pattern in some particular grid, customer service centers, and many more.

b. Deterministic simulation

Deterministic simulations are fixed and non random values that are used to define model of the system which is under investigation. The output of such system is fixed according to some specific inputs because of no randomness. Example: Chaotic model.

c. Terminating simulation

Terminating system may be defined as systems which have some natural event to occur and have some established starting and terminating condition. For example: A working day in an office starts at 9 am in morning and ends at $5 \mathrm{pm}$ in evening. In such systems, the established conditions generally affect some measurement in performance. So its basic function is to understand the behavior of the transient system.

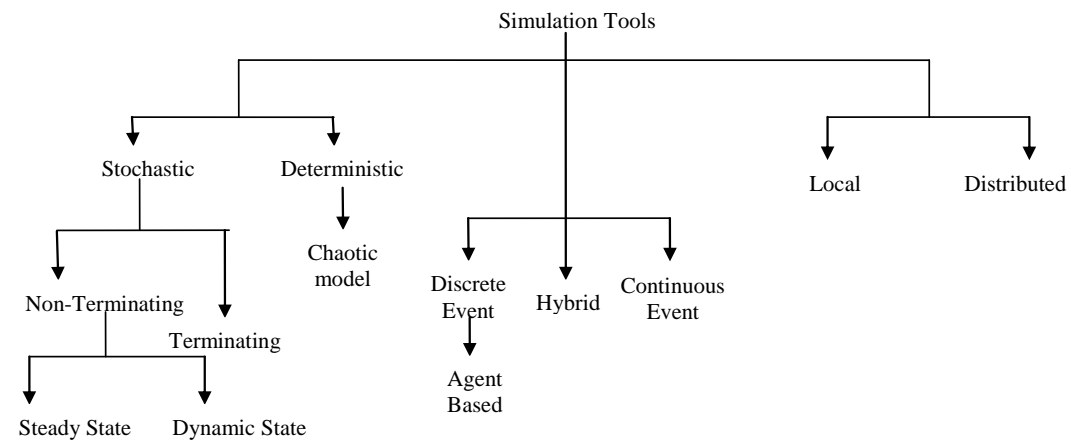

Figure 3. Classification of simulation tools

d. Non-terminating simulation

Non-Terminating systems are those systems that do not have a finite duration. For Example: The Internet. These simulation tools are used to explore long term behavior of systems. Of-course such type of systems stops at some point but it is a non-trivial problem to determine proper time.

e. Steady state simulation

Steady State simulation models are used to define the relationship between elements of system and the state in which equilibrium state occurs in system with the help of some equations.

f. Dynamic simulation

Dynamic simulation models are those models which results in change in system as input signals changes.

g. Discrete event simulation

Discrete event simulations are those models which organize events on time basis. In such type of simulations, a queue of events has been made by simulator on the basis of time in which they occur. Then the simulator reads the event queue by queue and new event is entered as the previous one is executed. Most of simulation tools came under this category like computers, fault-tree and logic-test simulators. Agent Based simulators is a special case of this simulator in which mobile entities are known as agents. However, in case of traditional discrete event model, entities have only attributes but agents have both attributes as well as methods which includes rules for interacting with other agents.

h. Continuous event simulators

Bulletin of EEI Vol. 6, No. 1, March $2017: 62-69$ 
Continuous simulators are of opposite nature as compared with discrete simulators as they solve differential equations which show the evolution of system using continuous equations. Such type of simulation works continuously and smoothly with any information rather in discrete steps. For- Example: The movement of water through chain of pipes and reservoirs can be described by continuous simulator.

i. Hybrid simulators

Hybrid simulations are those tools which combine both the features of continuous as well as discrete simulators and it can solve differential equations only if it is superimpose on continuous systems.

j. Local simulators

Local simulator models are those models which run within an interconnected network or on individual machine.

k. Distributed simulators

Distributed simulator models are those models which run over a network of interconnected computers basically through the Internet. So the simulation which scattered over many host computers is referred to known as distributed simulations.

\section{Open Source Software \& Network Simulators}

Open Source software (OSS) is free licence software which means that every user can freely study the source code, modify it and can distribute it [6]. It can be used for variety of applications viz office documentation, communication, web designing, and content management. Open Source Network simulators are of different types viz NS2, NS3, OMNET++, JSIM, OPNET, QualNet, MATLAB, etc. Some of these simulators are as explained below:

\subsection{NS2 (Network Simulator Version2)}

Network Simulator $[3,6,7,11-20]$ is also known as discrete event simulator that can support simulation of TCP, multicast protocols and routing over wireless and wired networks. NS2 has been developed in 1995 under Virtual Inter Network Test-bed (VINT) with the joint effort from University of Southern California's Information Sciences Institute, University of California at Berkeley, Xerox Palo Alto Research Centre and, Lawrence Berkeley National Laboratory. Defense Advanced Research Projects Agency and the National Science Foundation are the main sponsors of NS2. The various modules for mobile wireless network simulation i.e radio propagation models, the IEEE 802.11 MAC protocol, ad-hoc routing protocols (i.e AODV, DSR), Mobile IP and mobility models are provides by Monarch Project. NS2 is further extended by SensorSim to support simulation for sensor networks.

Key Features $[6,7,12,15,16,20]$ :

- It can be designed for parallel and distributed simulation (PDNS) and the results achieved are really good (Closer to reality) for simulation designing.

- It is available free of cost and has ample collection of models.

- Its Source code can be easily modified by the researchers.

Limitations [6, 7, 12, 15, 16, 18]:

- The scalability of NS2 is very small in terms of memory usage and simulation time in Wireless Sensor Networks (WSNs), peer to peer networks and in networks where hundreds of nodes are used.

- Energy consumed by hardware, software's and components of WSN nodes cannot be measured.

\subsection{NS3 (Network Simulator Version3)}

NS-3 simulator $6,7,10,14,15,19,20]$ is also a discrete event network simulator started in 2006 for research and educational use and is free software which is licensed under GNU GPLv2. The main features of NS3 as compared to NS2 are as follows:

- Modular, documented core.

- $\mathrm{C}++$ programs with Python scripting

- Closer to Real systems

- Software integration

- Integration of test-bed and Virtualization 
- Attribute system

- Updated models

Key Features $[6,7,15,20]$ :

- It shows good scalability characteristics; as it in integrated with architectural characteristics and carries code from GTNetS.

- It is also capable of performing large scale network simulations in efficient way.

- In works well in term of memory usage.

- It solves the problem of credibility.

Limitations [6, 7, 15]:

- It does not have all the simulation models that NS2 has currently because it is still in its developing stage.

- Also it does not have the capabilities like Use of IP addressing, design and alignment with Internet protocols, handling multiple interfaces, details about 802.11 models etc.

\subsection{OMNET++ (Objective Modular Network Testbed in $\mathbf{C}_{++}$)}

OMNET ++ $[3,6-9,11-14,16-20]$ is a general purpose, extensible, modular, componentbased, open architecture discrete event based network simulator. It is licensed under own Academic Public License only in non commercial settings. It is most commonly used for the simulation of computer networks, queuing network simulations etc. An OMNET++ simulation contains so many simple modules which forms the atomic behavior of a model. It runs on Linux, other UNIX-like systems and on Windows (XP, Win2K), MAC-OS.

Key Features [6, 7, 12, 16, 20]:

- It is very well structured simulator and it is not just limited to network protocol simulations like NS2.

- It's one of the main feature is that its modules can be reusable and it can be combined in a number of ways.

- It is based on $\mathrm{C}_{++}$language for modeling communication networks, and other distributed systems.

- It supports some MAC protocols and some localized protocols in Wireless sensor networks.

Limitations $[6,7,12,16,18]$ :

- Some scenarios and simulations cannot be implemented and performed in these simulators because some of the features are not present.

- Limited protocols are available.

\subsection{JSIM (Java-Based Simulation)}

JSIM [3, 6, 7, 10-14, 16-19] as the name suggest, it is a Java based simulation system which is used for analysis and building of quantitative numeric models with respect to the reference data of experiments. It is freely available with source code. Basically, JSIM provides application development environment with architecture of component based architecture. JSIM has been developed by a team at DRCL (Distributed Real-time Computing Laboratory) which was sponsored by DARPA's Information Technology Office, Air Force Office of Scientific Research's Multidisciplinary University Research, National Science Foundation (NSF), the Ohio State University and the University of Illinois at Urbana Champaign.

Key Features $[6,7,12,16]$ :

- It shows good scalability as compared with other simulators.

- It provides a platform which is independent, reusable and extensible.

- Protocols and components of wired as well as wireless networks can be implemented in it.

Limitations $[6,7,12,16,18]$ :

- More complicated to use after NS2.

- Less efficient and overhead occurs in communication models due to use of Java Language.

\subsection{OPNET (Optimized Network Engineering Tools)}

OPNET $[3,10,13,14,16-20]$ is a discrete event network simulator written in $\mathrm{C}_{++}$and proposed in 1986 by MIT. It is well established and mostly used commercial available simulation software. However, it can be used by researchers in Universities, colleges programs; free of cost. Also it supports various network hardware likes antennas and transceivers. The most important feature of OPNET is its ability to monitor and execute various scenarios in 
simultaneously. It allows users with the help of graphical interface to develop models and graphs. OPNET Modeler provides various features like designing, study of protocols, networks, devices and applications. This modeler runs on Window XP and Linux platform.

Key Features [16, 20]:

- Parameters of models can be changed.

- Provides a rich set of modules for each protocol stacks like IEEE802.11, IEEE 802.15.4 and various routing protocols viz AODV and DSR.

Limitations [16, 18]:

- Scalability problem is there due to object oriented design.

- Number of protocols available is less.

\subsection{QUALNET}

QUALNET [3, 7, 10,14, 16-20] simulator is a commercial ad-hoc network simulator which has been developed by Scalable Network Technologies and is based on GloMoSim protocol. Qualnet provides an environment to user to design new protocol models, enhance the new or existing protocols, design wired as well as wireless networks with the help of existing models and analyze their performance. Source code present in model helps the developers to build up new functions as well as modify the existing ones. The key features of Qualnet are speed, scalability, extensibility etc. It is written in Parsec (C-based) as it is built on top of GloMoSim.

Key Features [7, 16]:

- Easy to use and learn.

- Easy to stimulate large and heterogeneous network.

Limitations [16]:

- User friendly codes are limited due to availability of many in built functions.

\subsection{MATLAB}

MATLAB [3, 24] stands for mathematical laboratory which has been founded in 1984 by the Math Works and it provides an interactive software environment for programming. It is written in $C$ language and it supports cross platform operating system. It provides various command line functions as well as tools for measuring, analysis and visualization of data like digital filtering, signal processing and modulation of signaling etc. It is also used for generating waveforms and building test systems. It provides several applications to scientists, engineers, researchers and educators for technical computing.

With the help of MATLAB, one can

- Develop Algorithms for Digital Signal Processing.

- Model and simulate the systems.

- Create codes for MCUs, Embedded DSPs, and ASICs etc automatically.

- Verify and validate the software and hardware implementations.

Key Features [3]:

- Provides numerical computation and visualization of data.

- Provides tools for improving the quality of codes; so that its performance can be maximized in particular application.

Limitations [3]:

- Processing speed is slow.

- Excellent programming skills are required.

4. Comparative Study of Various Network Simulators

Table 1 shows the comparative study of the different open source simulators (NS2, NS3, J-Sim, OMNeT++, OPNET, QUALNET and MATLAB)[3, 6, 7, 9, 10, 15-17, 19, 21-23].

Table 1. Comparison of Different Open Source Simulator (Ns2, Ns3, J-Sim, Omnet++, Opnet, Qualnet and Matlab) 


\begin{tabular}{|c|c|c|c|c|c|c|c|c|}
\hline \multirow[b]{2}{*}{$\begin{array}{l}\text { S. } \\
\text { No }\end{array}$} & \multirow[b]{2}{*}{ FEATURES } & \multicolumn{7}{|c|}{ SIMULATORS } \\
\hline & & NS2 & NS3 & J-Sim & $\begin{array}{c}\text { OMNET } \\
++\end{array}$ & OPNET & $\begin{array}{c}\text { QUALN } \\
\text { ET }\end{array}$ & MATLAB \\
\hline 1 & Applicability & $\begin{array}{l}\text { Network/ } \\
\text { System }\end{array}$ & $\begin{array}{l}\text { Network/ } \\
\text { System }\end{array}$ & Network & $\begin{array}{l}\text { Network/ } \\
\text { System }\end{array}$ & $\begin{array}{l}\text { Network/ } \\
\text { System }\end{array}$ & $\begin{array}{l}\text { Network/ } \\
\text { System }\end{array}$ & System \\
\hline 2 & $\begin{array}{l}\text { Interface or } \\
\text { Language } \\
\text { used }\end{array}$ & $\begin{array}{c}\mathrm{C}++/ \mathrm{OT} \\
\mathrm{cl}\end{array}$ & $\begin{array}{c}\text { Parsec } \\
\text { (C- } \\
\text { based) }\end{array}$ & Java & $\begin{array}{c}\mathrm{C}++/ \mathrm{NE} \\
\mathrm{D}\end{array}$ & $\begin{array}{l}\mathrm{C} \text { or } \\
\mathrm{C}++\end{array}$ & $\begin{array}{c}\text { Parsec } \\
\text { (C- } \\
\text { based) }\end{array}$ & $\mathrm{C}++$ \\
\hline 3 & Availability & $\begin{array}{c}\text { Tradition } \\
\text { al } \\
\text { model/ } \\
\text { Wireless } \\
\text { support/ } \\
\text { Ad-hoc } \\
\text { support/ } \\
\text { Advance } \\
\text { Wireless } \\
\text { Sensor } \\
\text { Network } \\
\text { Support }\end{array}$ & $\begin{array}{c}\text { Tradition } \\
\text { al } \\
\text { model } / \mathrm{W} \\
\text { ireless } \\
\text { support/ } \\
\text { Ad-hoc } \\
\text { Support }\end{array}$ & $\begin{array}{c}\text { Traditional } \\
\text { model/Wireles } \\
\text { s support/ } \\
\text { Ad-hoc } \\
\text { support/Advan } \\
\text { ce Wireless } \\
\text { Sensor } \\
\text { Network } \\
\text { Support }\end{array}$ & $\begin{array}{c}\text { Tradition } \\
\text { al } \\
\text { model/W } \\
\text { ireless } \\
\text { support/ } \\
\text { Ad-hoc } \\
\text { Support }\end{array}$ & $\begin{array}{c}\text { Tradition } \\
\text { al } \\
\text { model/W } \\
\text { ireless } \\
\text { support/ } \\
\text { Ad-hoc } \\
\text { support/ } \\
\text { Wireless } \\
\text { Sensor } \\
\text { Network } \\
\text { Support }\end{array}$ & 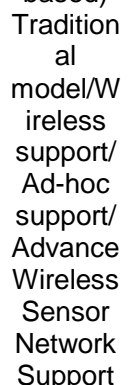 & $\begin{array}{c}\text { Data } \\
\text { Acquisition } \\
\text { Toolbox, } \\
\text { Instrument } \\
\text { Control } \\
\text { Toolbox, } \\
\text { Image } \\
\text { Acquisition } \\
\text { Toolbox }\end{array}$ \\
\hline 4 & Mobility & Support & Support & Support & No & $\begin{array}{l}\text { Support } \\
\text { Excellen }\end{array}$ & Support & Support \\
\hline 5 & $\begin{array}{l}\text { Graphical } \\
\text { Support }\end{array}$ & $\begin{array}{l}\text { No or } \\
\text { very } \\
\text { limited } \\
\text { Visual } \\
\text { Aid }\end{array}$ & $\begin{array}{l}\text { Limited } \\
\text { Visual } \\
\text { Aid }\end{array}$ & $\begin{array}{c}\text { Good } \\
\text { Visualization } \\
\text { and debug } \\
\text { facility }\end{array}$ & $\begin{array}{l}\text { Good } \\
\text { Visualiz } \\
\text { ation } \\
\text { and } \\
\text { excellent } \\
\text { debug } \\
\text { facility }\end{array}$ & $\begin{array}{c}t \\
\text { graphica } \\
\text { I } \\
\text { support, } \\
\text { Excellen } \\
\text { t facility } \\
\text { for } \\
\text { debug }\end{array}$ & $\begin{array}{c}\text { Good } \\
\text { graphica } \\
\text { I } \\
\text { support, } \\
\text { Excellen } \\
\text { t for } \\
\text { debug }\end{array}$ & $\begin{array}{l}\text { Excellent } \\
\text { graphical } \\
\text { support, } \\
\text { Excellent } \\
\text { facility for } \\
\text { debug }\end{array}$ \\
\hline 6 & License & $\begin{array}{l}\text { Open } \\
\text { Source }\end{array}$ & $\begin{array}{l}\text { Open } \\
\text { Source }\end{array}$ & Open Source & $\begin{array}{l}\text { Free for } \\
\text { Academi } \\
c \text { and } \\
\text { educatio } \\
n \text { use }\end{array}$ & $\begin{array}{l}\text { Free for } \\
\text { Academi } \\
c \text { and } \\
\text { educatio } \\
\text { n use }\end{array}$ & $\begin{array}{c}\text { Commer } \\
\text { cial }\end{array}$ & Commercial \\
\hline 7 & Scalability & Small & Large & Small & Large & Medium & $\begin{array}{l}\text { Very } \\
\text { Large }\end{array}$ & Very Large \\
\hline 8 & $\begin{array}{c}\text { Documentati } \\
\text { on \& } \\
\text { User } \\
\text { Support }\end{array}$ & $\begin{array}{c}\text { Excellen } \\
t\end{array}$ & $\begin{array}{c}\text { Excellen } \\
t\end{array}$ & Poor & Good & $\begin{array}{c}\text { Excellen } \\
t\end{array}$ & Good & Excellent \\
\hline 9 & Extendibility & $\begin{array}{c}\text { Excellen } \\
\mathrm{t}\end{array}$ & $\begin{array}{c}\text { Excellen } \\
t\end{array}$ & Excellent & $\begin{array}{c}\text { Excellen } \\
t\end{array}$ & $\begin{array}{c}\text { Excellen } \\
t\end{array}$ & $\begin{array}{c}\text { Excellen } \\
t\end{array}$ & Excellent \\
\hline 10 & Emulation & Limited & Limited & Yes & Limited & $\begin{array}{c}\text { Not } \\
\text { Direct }\end{array}$ & Yes & Yes \\
\hline
\end{tabular}

\section{Conclusion}

In this paper, the authors have surveyed on various simulation tools, open source software's, and open source network simulators along with their key features and limitations and their comparative study. All these open source network simulators (NS2, NS3, J-Sim, OMNeT++, OPNET, QUALNET and MATLAB) are useful for academic as well as industries point of view, as it helps students and researchers for doing research.

\section{References}

[1] Mrs. Saba Siraj, Mr. Ajay Kumar Gupta, Mrs Rinku-Badgujar. Network Simulation Tools Survey. International Journal of Advanced Research in Computer and Communication Engineering. June 2012; 1(4): 201-210.

[2] Sujata V Mallapur, Siddarama R Patil. Survey on Simulation Tools for Mobile Ad-Hoc Networks. IRACST - International Journal of Computer Networks and Wireless Communications (IJCNWC). April 2012; 2(2): 241-248.

[3] Mehta S Kwak, Najnin Sulatan. Network and system simulation tools for next generation networks: a case study. INTECH Open Access Publisher. 2010: 81-100.

[4] Heidemann, John, Kevin Mills, Sri Kumar. Expanding confidence in network simulations. IEEE Network 15. 2001; 5: 58-63.

[5] Sanchez Susan M. ABC's Of Output Analysis/Proceedings of the 2001 Winter Simulation Conference. Proceedings of the 1999 Winter Simulation Conference. 2001: 30-38.

Bulletin of EEI Vol. 6, No. 1, March $2017: 62-69$ 
[6] Suraj G Gupta, Mangesh M Ghonge, Parag D Thakare, Dr PM Jawandhiya. Open-Source Network Simulation Tools: An Overview. International Journal of Advanced Research in Computer Engineering \& Technology (IJARCET). April 2013; 2(4): 1629-1635.

[7] Mrs. Poonam Chhimwal, Dhajvir Singh Rai, Deepesh Rawat. Comparison between Different Wireless Sensor Simulation Tools. IOSR Journal of Electronics and Communication Engineering (IOSR-JECE). Mar. - Apr. 2013; 5(2): 54-60.

[8] Bartosz Musznicki, Piotr Zwierzykowski. Survey of Simulators for Wireless Sensor Networks. International Journal of Grid and Distributed Computing. September 2012; 5(3): 23-50.

[9] Miloš Jevtić, Nikola Zogović, Goran Dimić. Evaluation of Wireless Sensor Network Simulators. 17th Telecommunications forum TELFOR. 2009: 1303-1306.

[10] Abdelrahman Abuarqoub, Fayez Al-Fayez, Tariq Alsboui, Mohammad Hammoudeh, Andrew Nisbet. Simulation Issues in Wireless Sensor Networks: A Survey. SENSORCOMM: The Sixth International Conference on Sensor Technologies and Applications. 2012: 222-228.

[11] E Egea-López, J Vales-Alonso, AS Martínez-Sala, P Pavón-Mariño, J García-Haro. Simulation Tools for Wireless Sensor Networks. Summer Simulation Multiconference - SPECTS 2005: 2-9.

[12] Harsh Sundani, Haoyue Li, Vijay Devabhaktuni, Mansoor Alam, Prabir Bhattacharya. Wireless Sensor Network Simulators A Survey and Comparisons. International Journal of Computer Networks (IJCN). 2011; 2(5): 249-265.

[13] SG Shiva Prasad Yadav, Dr. A Chitra. Wireless Sensor Networks Architectures, Protocols, Simulators and Applications: a Survey. International Journal of Electronics and Computer Science Engineering. 1(4): 1941-1953.

[14] Christhu Raj MR, Namrata Marium Chacko, John major, Shibin D. A Comprehensive Overview on Different Network Simulators. International Journal of Engineering and Technology (IJET). Feb-Mar 2013; 5(1): 325-332.

[15] Rachna Chaudhary, Shweta Sethi, Rita Keshari, Sakshi Goel. A study of comparison of Network Simulator -3 and Network Simulator -2. International Journal of Computer Science and Information Technologies. 2012; 3(1): $3085-3092$.

[16] V Chandrasekaran, S Anitha, A Shanmugam. A Research Survey on Experimental Tools for Simulating Wireless Sensor Networks. International Journal of Computer Applications (0975 - 8887) October 2013; 79(16): 1-9.

[17] Vinita Mishra, Smita Jangale. Analysis and comparison of different network simulators. International Journal of Application or Innovation in Engineering \& Management (IJAIEM). Special Issue for International Technological Conference-2014.

[18] Murat Miran Koksal. A Survey of Network Simulators Supporting Wireless Networks. Department of Computer Science, Graduate School of Natural and Applied Sciences, Middle East Technical University, Ankara, TURKEY, October 22, 2008: 1-11.

[19] Piotr Owczarek, Piotr Zwierzykowski. Re view of Simulators for Wireless Mesh Networks. Journal of Telecommunications and Information Technology. March 2014: 82-89.

[20] Jianli Pan, Prof. Raj Jain Project. A Survey of Network Simulation Tools: Current Status and Future Developments. report.

[21] http://en.wikipedia.org/wiki/Network_simulation.

[22] http://www.omnetpp.org/

[23] http://en.wikipedia.org/wiki/QualNet

[24] https://en.wikipedia.org/wiki/MATLAB 